\title{
Tumor extragonadal de células germinales en mediastino: aportación de un caso
}

\author{
Zavala Elizondo A**, Martínez Montelongo R*, González JE.
}

U.A.N.L. Hospital Universitario Monterrey, N.L. México

Actas Urol Esp. 2008;32(3):357-359

\begin{abstract}
RESUMEN
TUMOR EXTRAGONADAL DE CELULAS GERMINALES EN MEDIASTINO: APORTACIÓN DE UN CASO

Los tumores de células germinales de origen extragonadal son descritos infrecuentemente en la literatura, siendo menos de 1.000 casos. Los sitios de origen por orden de frecuencia son mediastino, retroperitoneo, región sacro coccígea y glándula pineal. Este caso es de un germinoma primario en mediastino en un paciente de 27 años de edad. En los estudios de imagen se demostró una masa mediastinal, se tomo una biopsia para llegar al diagnóstico. Marcadores tumorales normales, el ultrasonido testicular reportó la presencia de microlitiasis bilateral. El paciente fue tratado con poliquimioterapia y resección de masa residual. La evolución fue satisfactoria con respuesta completa.

Palabras clave: Germinoma. Mediastino.

\section{ABSTRACT \\ EXTRAGONADAL GERM CELL TUMOR IN MEDIASTINUM: CASE REPORT}

The Germ Cell tumors of extragonadal origin are infrequent cases being described in literature less than 1000 cases. The frequent origin sites are mediastinum, retroperitoneum, sacrococcygeal region, and the pineal gland.

There was a primary case of germinoma in mediastinum in a 27 years patient.

In the image studies a mediastinal mass was demonstrated, a biopsy was taken arriving at the diagnosis.

Normal tumor markers, testicular ultrasonography reported the presence of bilateral microlitiasis.

It was treating with polychemotherapy and later residual mass was dried.

The evolution was satisfactory with complete answer.

Keyword: Germinoma. Mediastinum.
\end{abstract}

$\mathrm{P}$ aciente masculino de 27 años de edad refiriendo dos meses de evolución con edema facial de predominio matutino y disnea en posición de decúbito, sin otros síntomas. A la exploración física importante edema facial, sin adenomegalias y/o masa abdominal. Los exámenes de laboratorio solo mostraron leucopenia. La radiografía de tórax muestra una gran masa mediastinal (Fig. 1), y la resonancia magnética evidencia dicha masa en mediastino anterior (Figs. 2 y 3).

Los marcadores tumorales (alfa feto proteína (AFP) y gonadotropina coriónica humana subunidad beta (HCG)) normales. La ecografía testicular con ambos testículos de forma, tamaño, y ecogenicidad normal, micro litiasis bilateral (Fig. 4), sin presencia de lesiones ocupativa y con quiste de $2,8 \mathrm{~mm}$. en epidídimo izquierdo, se realiza toma de biopsia por trucut de masa mediastinal con resultado anatomopatológico de germinoma (Fig. 5), posteriormente se somete a paciente a tratamiento con quimioterapia, con posterior resección de masa residual del cual el reporte anatomopatológico indica la presencia de tejido necrótico con calcificación focal y granuloma tipo cuerpo extraño (Fig. 6), así como presencia de depósitos de colesterol y restos de timo, actualmente se encuentra con marcadores tumorales de control negativos, con una evolución satisfactoria y con respuesta completa al tratamiento. 


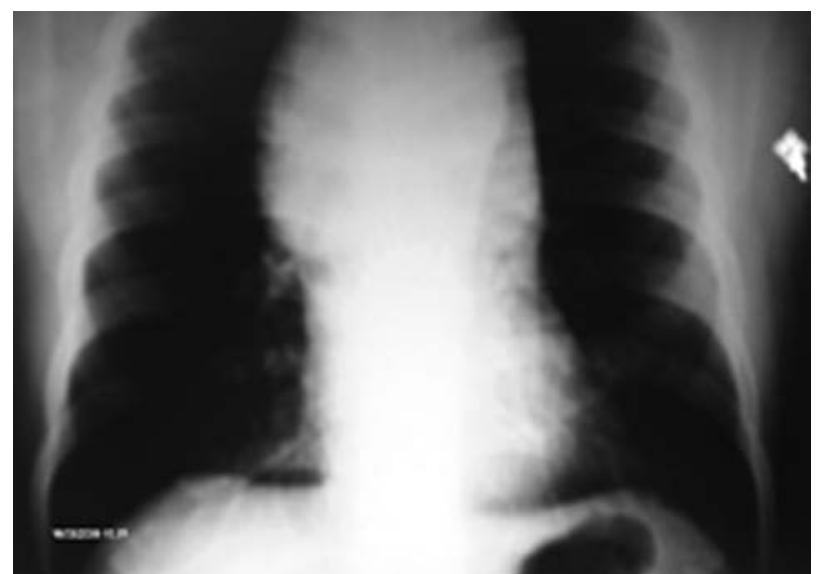

FIGURA 1. Presencia de ensanchamiento mediastinal en la tele de torax.
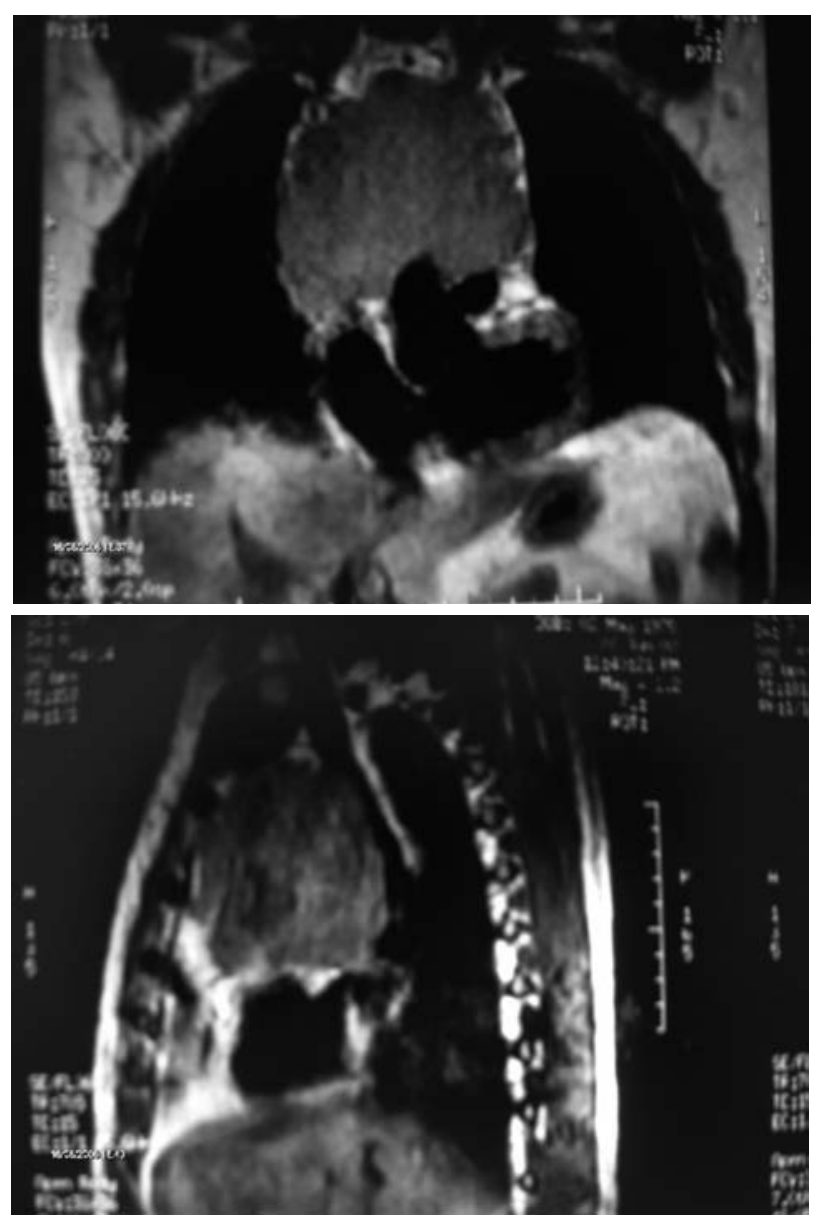

FIGURAS 2 y 3. RMN presencia de gran masa mediastinal.

\section{DISCUSION}

Los tumores germinales de origen extragonadal se presentan en un 3 a $5 \%$, siendo raros y descritos en la literatura menos de 1000 casos. Los sitios de origen en orden decrecente de frecuencia son

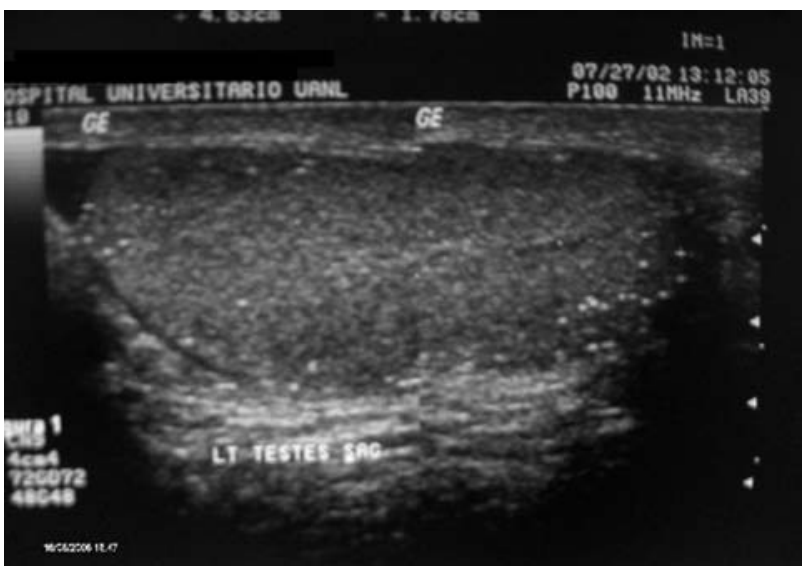

FIGURA 4. Ultrasonido. Presencia de múltiples microlitiasis testiculares.

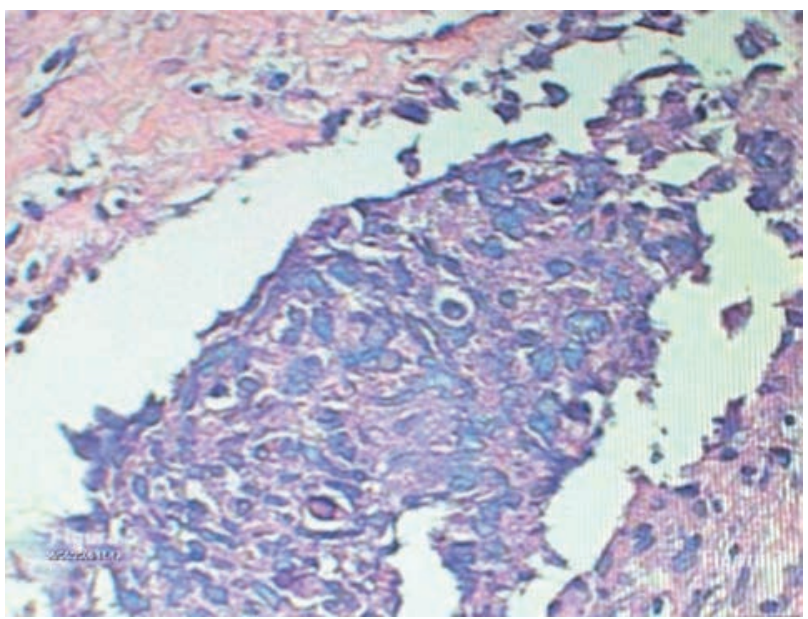

\section{FIGURA 5}

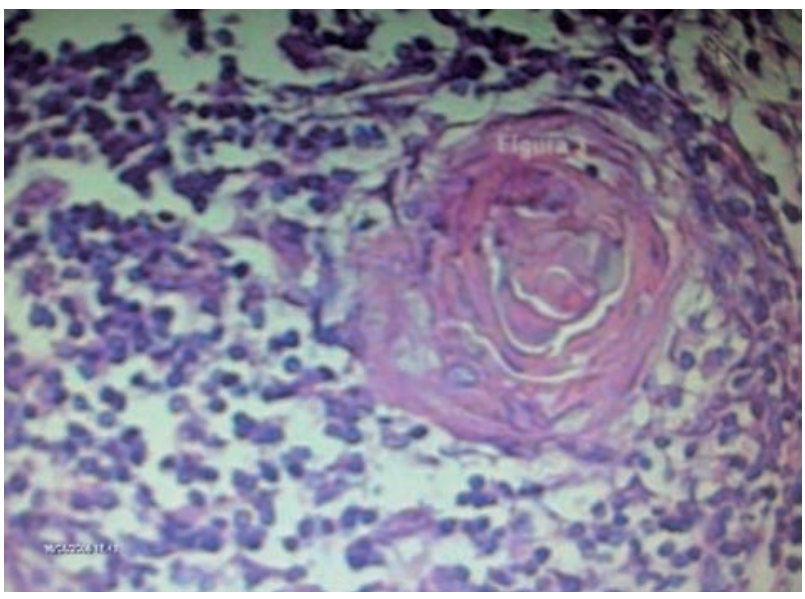

\section{FIGURA 6}

mediastino, retroperitoneo, región sacrococcígea y glándula pineal. También se encuentran casos reportados en la literatura en la próstata ${ }^{1}$. Predomina en hombres en la tercera década de la vida con síntomas como dolor torácico, tos, y disnea, aunque la mayoría 
se presenta con enfermedad local avanzada y metástasis distantes invadiendo nódulos linfáticos, pulmones, hígado y hueso. Histológicamente el seminoma puro representa la mitad de los casos. Algo que es importante mencionar es que la AFP se encuentra elevada en un $80 \%$ y la HCG en el 30 a $35 \%$ de estos casos de tumores de células germinales extragonada$l^{2}{ }^{2}$. En este caso el paciente presentaba marcadores tumorales negativos los cuales se han mantenido así hasta la fecha, así como la asociación de microlitiasis testicular bilateral que según nuestro conocimiento no hay casos descritos en la literatura médica. Existen algunos otros marcadores como el CA19-9 que se eleva frecuentemente en el carcinoma embrionario, en otros casos existe elevación del marcador DU-PAN-2 que es un marcador para canceres gastrointestina$l^{3}{ }^{3}$. El tratamiento de elección en la quimioterapia basada en cisplatino, bleomicina y etopósido.

\section{REFERENCIAS}

1. Kitsukawa SI, Kin T, Tsukamoto T, Yonese J, Ishikawa Y, Fukui I.Extragonadal germ cell tumor of mediastinum with high serum level of carcinoembryonic antigen and carbohydrate antigen 199 J Urol. 2000 Mar;163(3):912-913.

2. Kleinhans B, Kalem T, Hendricks D, Arps H, Kaelble T. Extragonadal germ cell tumor of the prostate. J Urol. 2001 Aug;166 (2):611-612.

3. Maeda Y, Fujiwara N, Yoshino T, Kiura K, Ueoka H, Harada M. Extragonadal germ cell tumor with high serum levels of DUPAN-2 J Urol. 2002 Jan;167(1):246-247.

Correspondencia autor: Dr. A. Zavala Elizondo Hospital Universitario Dr. José Eleuterio González Universidad Autónoma de Nuevo León

Avda. Francisco I. Madero y Av. Gonzalitos, s/n

Colonia Mitras Centro. Monterrey, Nuevo León, Mexico Tel.: (0181) 83331713

E-mail autor: elzavala4@yahoo.com

Información artículo: Nota Clínica

Trabajo recibido: septiembre 2006

Trabajo aceptado: julio 2007 